\title{
Granulomatous Diverticulitis: Who Would Have Thought!
}

\author{
Fady G. Haddad ${ }^{1}$, Sandy El Bitar ${ }^{2}$, Hassan Al Moussawi ${ }^{3}$, Liliane Deeb ${ }^{1}$
}

1. Gastroenterology and Hepatology, Staten Island University Hospital, New York, USA 2. Internal Medicine, Staten Island University Hospital, New York, USA 3. Medicine, Staten Island University Hospital, New York, USA

Corresponding author: Fady G. Haddad, fadi.haddad7@hotmail.com

\begin{abstract}
Diverticular disease (DD) can have different presentations, including chronic colitis. However, diverticular disease-associated colitis (DAC) is a separate entity that can be associated with a granulomatous inflammation. DAC usually affects the left colon with no involvement of the cecum and the ascending colon. In this setting, Crohn's disease is high in the differential diagnosis. Although granulomatous colitis associated with diverticulosis has been previously described, this is the first case affecting the right colon to be reported in the English literature according to our search of the PubMed database. The patient presented with a tumor-like mass abutting the right colon that was further diagnosed as a granulomatous reaction secondary to DAC.
\end{abstract}

Categories: Internal Medicine, Gastroenterology, General Surgery

Keywords: diverticulosis, segmental diverticulitis, granulomatous, segmental colitis associated with diverticulosis, diverticular disease associated colitis

\section{Introduction}

Diverticular disease (DD) encompasses a broad scope of manifestations, including chronic colitis. Diverticular disease-associated colitis (DAC) is a distinct entity that can occasionally exhibit granulomatous inflammation. It usually affects the left colon, excluding the cecum and the ascending colon. In this setting, caution is advised to avoid an inappropriate diagnosis of Crohn's disease. Although granulomatous colitis associated with diverticulosis has been previously described, our patient is the first case affecting the right colon to be reported in the English literature based on our search of the PubMed database. He presented with a hypermetabolic tumor-like mass abutting the right colon that was further identified as a granulomatous reaction secondary to DAC.

\section{Case Presentation}

A 77-year-old man with diabetes mellitus and hypertension presented with right lower quadrant (RLQ) abdominal pain that started a few weeks prior to his presentation. Physical examination revealed a palpable RLQ mass. An abdominal computed tomography (CT) scan revealed a $5.5 \mathrm{~cm}$ irregular soft tissue mass

Received 01/30/2018

Review began 03/12/2018 Review ended 06/08/2018 Published 06/13/2018

\section{() Copyright 2018}

Haddad et al. This is an open access article distributed under the terms of the Creative Commons Attribution License CC-BY 3.0., which permits unrestricted use, distribution, and reproduction in any medium, provided the original author and source are credited. abutting the ascending colon medially (Figures 1,2).

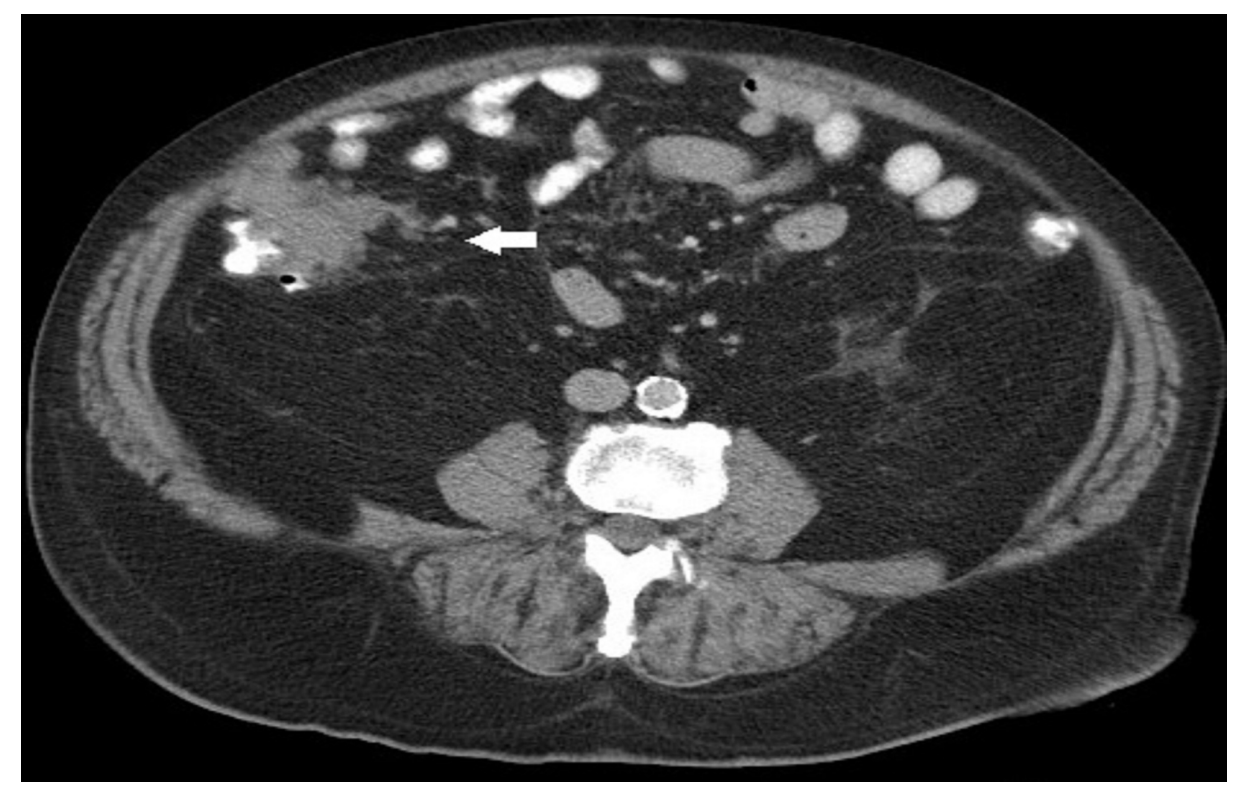




\section{Cureus}

FIGURE 1: Abdominal computed tomography scan, axial view, showing an irregular $5.5 \mathrm{~cm}$ soft tissue mass abutting the right colon medially

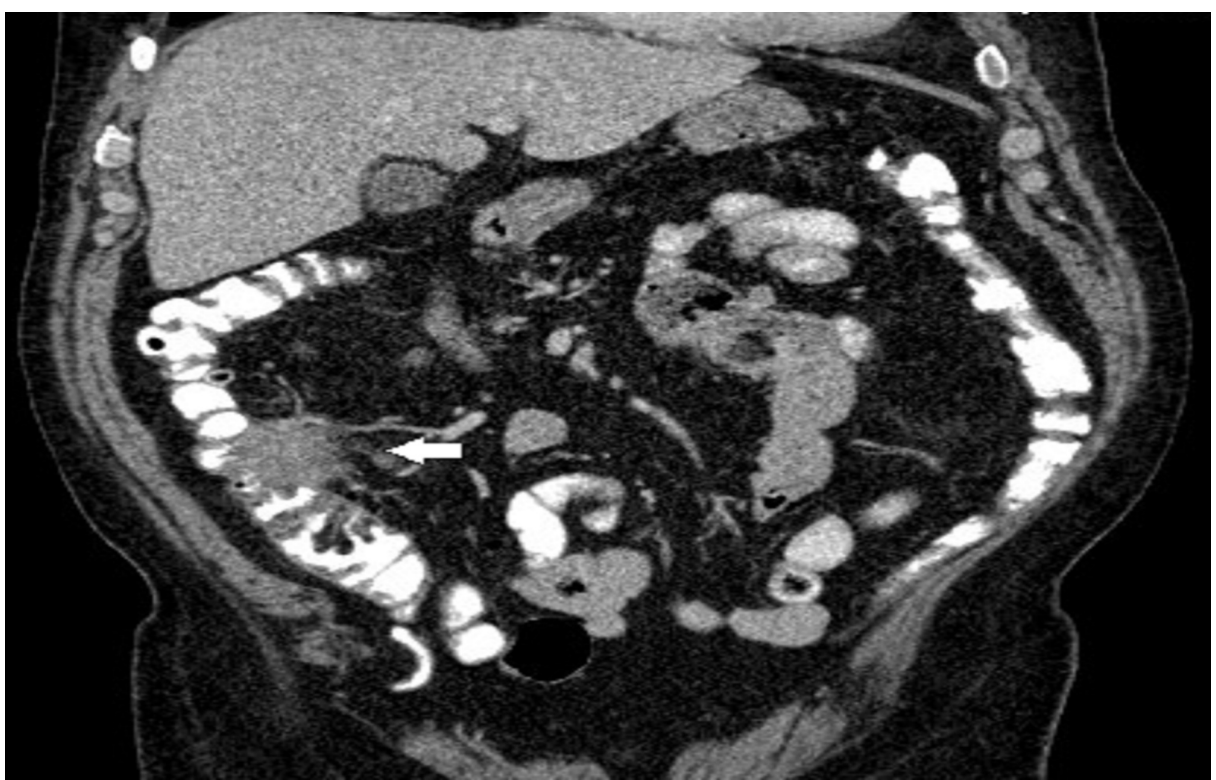

FIGURE 2: Abdominal computed tomography scan, coronal view, showing an irregular $5.5 \mathrm{~cm}$ soft tissue mass abutting the right colon medially

Colonoscopy revealed diverticulosis in the sigmoid and ascending colon. On positron emission tomography (PET) scan, the mass exhibited increased metabolic activity suspicious for biological tumor activity (Figure 3).

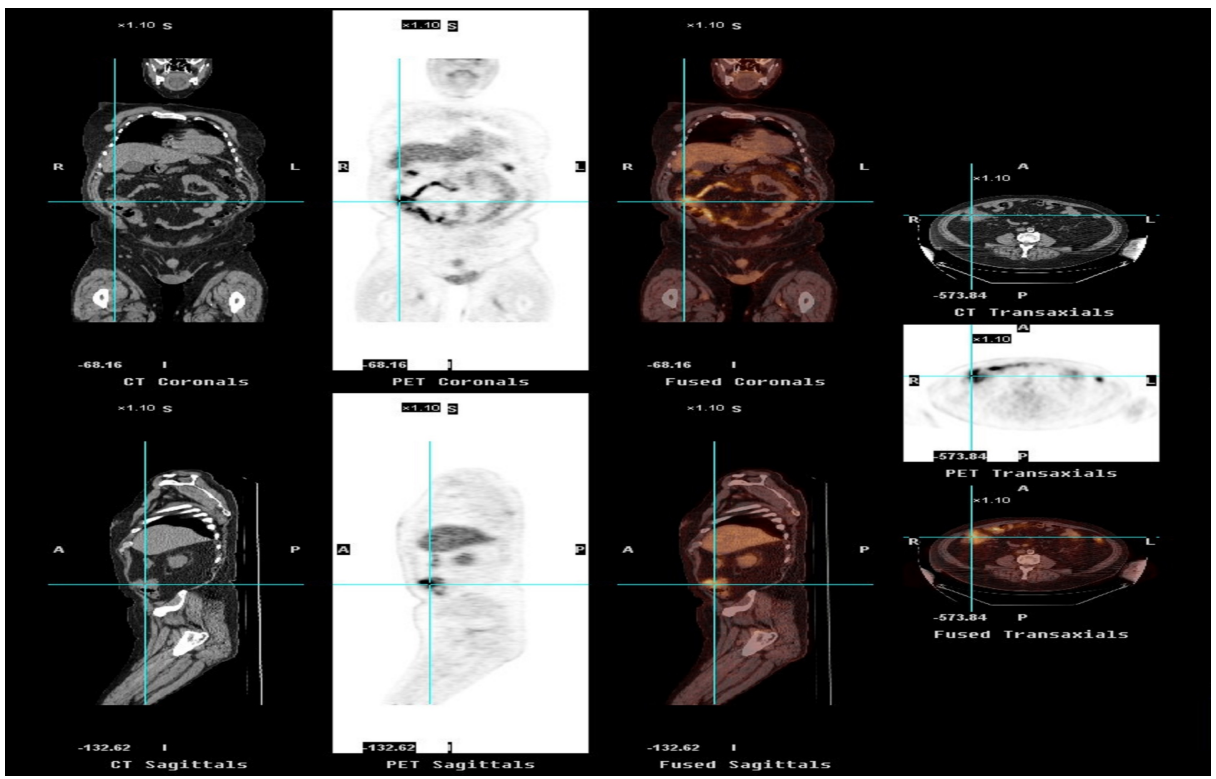

FIGURE 3: PET scan showing increased metabolic activity of the mass suspicious for biological tumor activity

PET: positron emission tomography 


\section{Cureus}

A CT-guided biopsy revealed inflammatory cells. The patient underwent a diagnostic laparoscopy, and a fresh frozen section was inconclusive for malignancy. This was followed by a robotic-assisted right hemicolectomy en bloc with the mass. Pathology showed diverticulitis with localized suppurative granulomatous inflammation in pericolic fat (Figure 4).

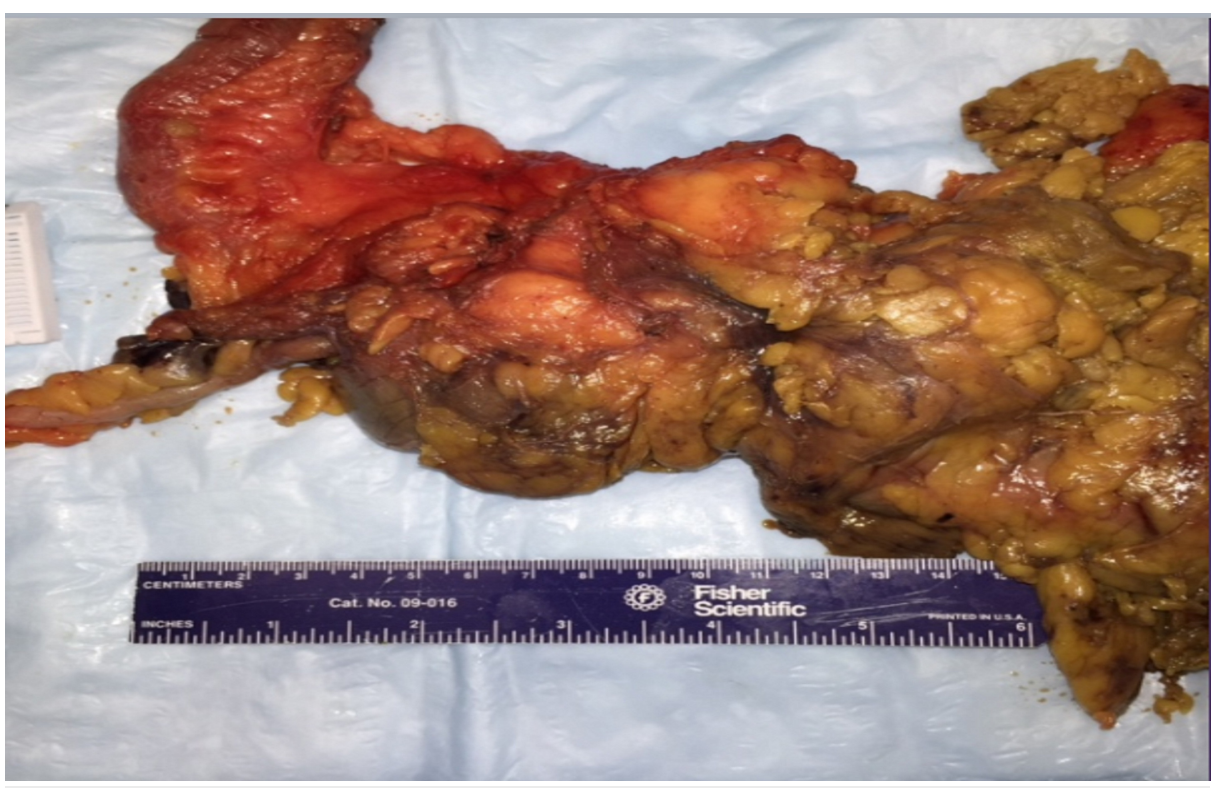

\section{FIGURE 4: Gross pathology showing diverticulitis with localized suppurative granulomatous inflammation in the pericolic fat}

The non-caseating granulomas consisted of epithelioid histiocytes with abundant eosinophilic cytoplasm and eccentric nuclei (Figure 5A). Immunostains were positive for CD68 (Figure 5B) and vimentin (Figure 5C) and negative for pancytokeratin (Figure 5D), eliminating the possibility of a carcinoma or sarcoma.
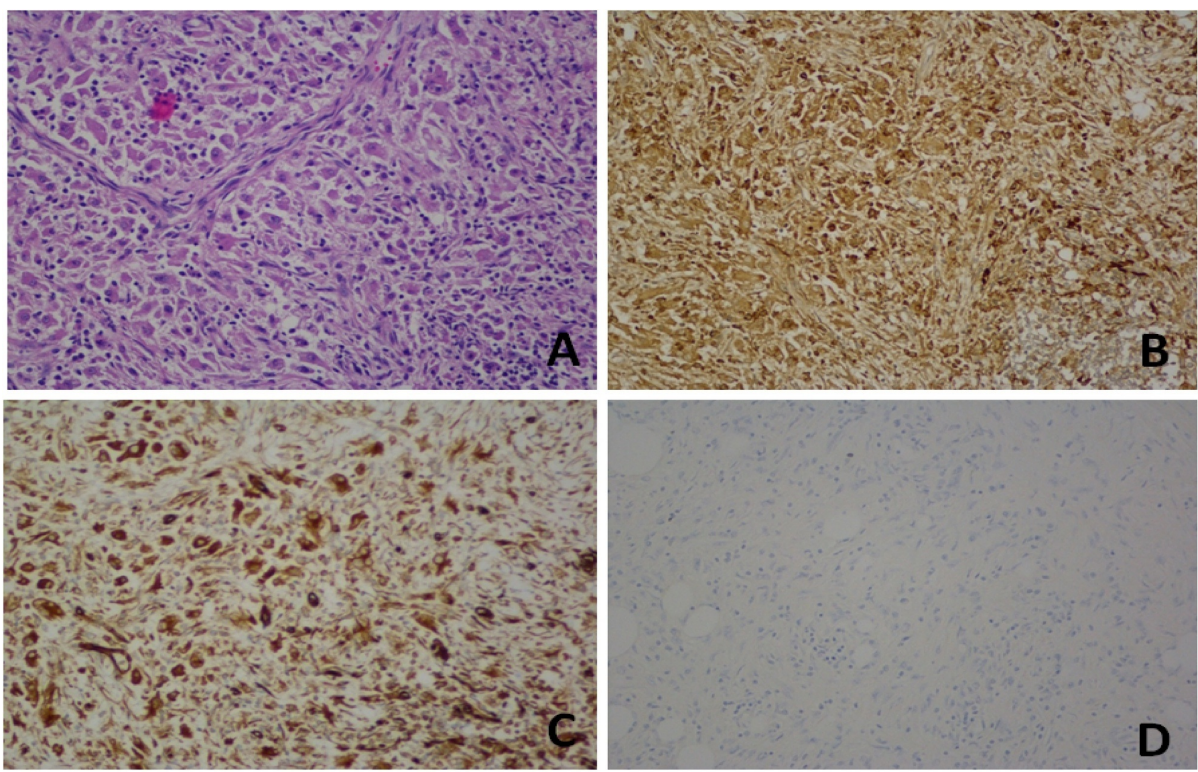

\section{FIGURE 5: Pathology images}

Pathology images showing the non-caseating granulomas consisting of epithelioid histiocytes with abundant eosinophilic cytoplasm and eccentric nuclei (A). Immunostains were positive for CD68 (B) and vimentin (C) and negative for pancytokeratin (D).

The patient improved clinically and was successfully discharged after few days of his surgery. 


\section{Discussion}

DD is a leading cause of hospitalizations in developed countries affecting $30-50 \%$ of individuals older than 60 years [1-2]. DAC describes the occurrence of mucosal inflammation in a colon segment affected with DD with relative sparing of the rectum and proximal colon. Its prevalence is suggested to be approximately 1.3 3.8\% [1-2]. Pathogenesis is multifactorial with multiple reports noting clinicopathological overlap between DAC and inflammatory bowel diseases (IBD), especially in patients with granulomatous colitis, as in our case (Haddad FG, et al.: A Pseudotumor? No! It's a Granulomatous Diverticulitis in Disguise! American College of Gastroenterology 82nd annual mtg., Orlando, FL, Oct. 13-18, 2017, abstract \#1426.

http://www.nature.com/articles/ajg2017312.pdf). Recurrence rates and long-term outcomes of DAC are not well-defined and could range from a benign course to an overt IBD. More studies are needed in order to further characterize this entity [1-4].

\section{Conclusions}

Diverticular disease-associated colitis is a known but uncommon presentation of diverticular diseases. A clinical and pathologic overlap between this entity and inflammatory bowel diseases, namely, Crohn's disease, poses a diagnostic and therapeutic dilemma in the management of affected individuals. In addition, rates of recurrence and long-term outcomes are not well-defined, ranging from a benign course to manifestations of overt IBD. More studies are needed in order to further characterize this entity.

\section{Additional Information}

\section{Disclosures}

Human subjects: Consent was obtained by all participants in this study. Conflicts of interest: In compliance with the ICMJE uniform disclosure form, all authors declare the following: Payment/services info: All authors have declared that no financial support was received from any organization for the submitted work. Financial relationships: All authors have declared that they have no financial relationships at present or within the previous three years with any organizations that might have an interest in the submitted work. Other relationships: All authors have declared that there are no other relationships or activities that could appear to have influenced the submitted work.

\section{References}

1. Burroughs SH, Bowrey DJ, Morris-Stiff GJ, Williams GT: Granulomatous inflammation in sigmoid diverticulitis: two diseases or one?. Histopathology. 1998, 33:349-53. 10.1046/j.1365-2559.1998.00521.x

2. Jun S, Stollman N: Epidemiology of diverticular disease. Best Pract Res Clin Gastroenterol. 2002, 16:529-42. 10.1053/bega.2002.0328

3. Rampton DS: Diverticular colitis: diagnosis and management. Colorectal Dis. 2001, 3:149-53. 10.1046/j.1463-1318.2001.00242.x

4. Haddad F, El Bitar S, Al Moussawi H, et al.: Diverticular disease-associated colitis: what do we know? A review of literature. Cureus. 2018, 10:e2224. 10.7759/cureus.2224 